\title{
Tooth Carving as a Teaching Modality in the Study of Tooth Morphology: Students' Perception and Performance
}

\author{
Madiha Anwar ${ }^{1}$ \\ Beenish Fatima Alam ${ }^{2}$ \\ Syed Jaffar Abbas Zaidi ${ }^{3}$
}

\author{
BDS \\ BDS, MFDS, MSc \\ MD, MFDS, MFD, MSc, FAIMER
}

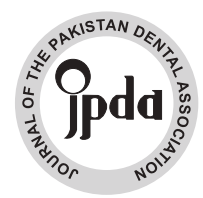

OBJECTIVE: Dental wax carving exercise is a practical exercise to teach tooth morphology that develops psychomotor skills needed to practice clinical dentistry. This study aimed to determine the efficacy of dental wax carving as a teaching modality for tooth morphology and its assessment.

METHODOLOGY: Forty-two first-year dental students were randomly divided into two groups participated in this study from February 2019 till September 2019 at Bahria University Medical \& Dental College. Learning resources related to dental wax carving were provided to the first group of 21 students while the second group of 21 students received practical demonstration. The students self-evaluated their dental carving based on a standardized checklist and two examiners then evaluated the dental wax carvings randomly. A student satisfaction survey was performed at the end of this study to gain feedback regarding the dental wax carving as a teaching methodology.

RESULTS: The mean scores given by self-assessment of students were significantly higher than those given by the examiners to both the groups. The group that was given a live demonstration of dental carving scored higher than the self-directed learners. Overall student feedback regarding dental carving was uniformly positive.

CONCLUSION: Dental carving skills develop manual dexterity and psychomotor skills for practicing clinical dentistry and should be an integral component of preclinical dental curriculum so that clinically relevant cognitive \& psychomotor skills are incorporated. Based on this study, a live demonstration of dental wax carving skills should be the preferred teaching modality. KEYWORDS: Dental carving, tooth carving, wax carving, psychomotor skills, dental anatomy, restorative dentistry HOW TO CITE: Anwar M, Alam BF, Zaidi SJA. Tooth carving as a teaching modality in the study of tooth morphology: Students' perception and performance. J Pak Dent Assoc 2020;29(4):249-253.

DOI: https://doi.org/10.25301/JPDA.294.249

Received: 11 April 2020, Accepted: 04 July 2020

\section{INTRODUCTION}

$\mathrm{T}$ he aesthetic sense of a dentist needs to be developed from the point where the undergraduate student starts learning dental anatomy and tooth morphology. ${ }^{1}$ A dentist should have comprehensive knowledge regarding the morphology and function of teeth, as it provides the basis for a dentist to be able to restore the missing tooth structure with the help of restorative material. ${ }^{2}$ Along with the theoretical knowledge of tooth structure and its function, for proper restoration, it is crucial to have technical skills, manual dexterity and above all an artistic sense. ${ }^{3}$ Only then a clinician will be able to reproduce anatomical details to make the dental restoration appear as natural as possible. ${ }^{4}$

1. Senior Lecturer, Department of Oral Biology, Bahria University Medical \& Dental College, Karachi.

2. Assistant Professor, Department of Oral Biology, Bahria University Medical \& Dental College, Karachi.

3. Assistant Professor, Department of Oral Biology, Dow Dental College, Dow University of Health Sciences, Karachi.

Corresponding author: “Dr. Syed Jaffar Abbas Zaidi” < jaffar.zaidi@duhs.edu.pk >
Psychomotor skills of dental students related to dental carving need to be developed early on so that manual dexterity in recreating adequate tooth form may be achieved for restorative clinical procedures and functional purposes. ${ }^{5,6}$

In pre-clinical years, dental anatomy and tooth morphology is the first subject that introduces dental students to human teeth's structure and function. ${ }^{7}$ The knowledge of tooth morphology, alignment and occlusion is critical for identification of teeth as well as to relate the morphology of teeth with function in health and disease. At this initial stage, it is important to develop the psychomotor skills of the students which will, later on, help them in identifying the details of the tooth surface as well as the changes in the structure in disease or pathology. ${ }^{8}$ Oral anatomy and tooth morphology have been traditionally taught by didactic lectures, books, manuals, artificial tooth models and extracted teeth. ${ }^{9}$ Wheeler's ${ }^{10}$ was one of the first who introduced tooth carving in wax blocks. In many dental schools, all over the world, tooth carving is an integral part of the curriculum where the students are required to carve a tooth from an 
oversized wax block or soap bar., ${ }^{4,9,11-14}$ The carved tooth approximates the dimensions of the natural teeth and it is intended to re-create the different positive and negative anatomical features such as cusps, cingulum, ridges, fossae and grooves. ${ }^{15}$ The main purpose of tooth carving is to recreate accurate anatomical and morphological landmarks of the permanent and deciduous dentition for physiological function and harmony of teeth. The main ethos of dental wax carving is to nurture the fine art of waxing teeth by restoring them to their correct morphology and anatomy. Every tooth in the dental arch has six surfaces and every surface of the tooth has unique distinguishing and identifying features. None of these surfaces is flat. Dental wax carving is an exercise in learning to duplicate the contours and convexities and concavities unique to the tooth type and location. The skills involved in dental wax carving familiarizes dental students with hand instrumentation techniques and allows them to develop skills such as finger dexterity, grip, hand steadiness, aiming and reaction; all of which are essential for the high precision needed to practice dentistry.

Previously, at Bahria University Medical and Dental College, foundational knowledge of tooth morphology was traditionally presented in didactic lectures, textbooks and study guides while psychomotor skills of students were developed through two-dimensional line drawings of teeth and sketching projects of different views of the teeth in graph books. This traditional model of teaching was instilling only superficial understanding without any clinical significance or integration with clinical sciences. Feedback of students indicated that they were facing difficulty in interacting with patients as the first two years are predominantly technical introductory pre-clinical phase of dental education with no emphasis on developing psychomotor skills. Furthermore, they stated that the oral biology course was inadequate to prepare students from pre-clinical care to direct patient care. clinically relevant psychomotor skills were insufficiently being taught, thereby hindering student's ability to apply learning in direct patient care.

Carving of the tooth was introduced in the current academic year to promote self-directed active learning and to bring clinical relevance to the subject of oral biology. The objectives of this study was to examine the efficacy of a newly introduced systematic dental carving technique for teaching tooth morphology that relies on psychomotor and kinaesthetic learning to facilitate student transition from pre-clinical care to the clinical dental practice.Moreover, the effectiveness of self-directed learning and accuracy of self-assessment by the students was evaluated. The study also involved a brief survey about student's perception of dental carving.

\section{METHODOLOGY}

The study was conducted on forty-two students studying in the first undergraduate year of Bahria University Medical and Dental College. The intended research population was first year dental students and the entire population was included in the study by total population sampling so no formal size calculation was needed. ${ }^{16}$

All the participants signed consent forms and ethical approval was obtained from Institutional Review Board Reference No. (ERC 02/2019).

Maxillary central incisor was chosen for this study. The students were randomly divided into two study groups:

The 1 st group comprised of 21 students who were taught tooth morphology with the help of lectures, plaster models, sketching and drawing of various views of teeth. This group was provided with a handout regarding the steps involved in carving and they were asked to carve the tooth without any demonstration or help. The handout was adapted from Wheeler's tooth carving manual. ${ }^{10}$

The second group comprised of 21 students who were taught tooth morphology with the help of lectures, plaster models, sketching and drawing. Besides, they were given a step-by-step demonstration of tooth carving and handouts in their lab sessions.

The students were provided with a wax block that was $50 \mathrm{~mm}$ in length, $25 \mathrm{~mm}$ in width and $25 \mathrm{~mm}$ in depth. Both the groups had to carve a maxillary central incisor; Group I; had no previous demonstration about the steps, while Group II; carved the tooth after step by step practical demonstration given by the facilitator. The teeth were evaluated by both students and examiners. The teeth were coded, and examiners were randomly allocated carved teeth to ensure the integrity and validity of the results.

\section{GRADING CHART}

To standardize the grading of the teeth a grading chart was formulated based on the study conducted by Kilistoff et $\mathrm{al}^{17}$ (Table 1). This standardized chart had scored for different morphological features of the maxillary central incisor. The tooth was evaluated; 2 marks for each completed feature, 1 mark for complete feature and 0 for an absent feature.

The carved teeth of both groups were collected and coded. The carved teeth of 1 st group were randomly divided into students of the 2 nd group and vice versa. The students were asked to self-evaluate the teeth provided to them according to the grading chart. The teeth were then evaluated by two examiners who were randomly assigned carved teeth from either group. The examiners evaluated the teeth on the same grading chart. 
Table 1: Marking chart for tooth carving

\begin{tabular}{|c|c|c|c|}
\hline \multirow{2}{*}{$\begin{array}{l}\text { Features of the tooth } \\
\text { Geometric form }\end{array}$} & Maxillary central incisor & SCORE $^{*}$ & $/ 30$ \\
\hline & $\begin{array}{l}\text { Labial surface - rectangular } \\
\text { Lingual surface - spoon-shaped } \\
\text { Proximal surfaces - triangular } \\
\text { The shape of the root - conical }\end{array}$ & $\begin{array}{ll}0 & 1\end{array}$ & 2 \\
\hline Measurements & $\begin{array}{l}\text { Cervico-incisal length }=10.5 \\
\mathrm{~mm} \\
\text { Root length }=13 \mathrm{~mm} \\
\text { Mesio-distal diameter of crown } \\
=8.5 \mathrm{~mm} \\
\begin{array}{l}\text { Mesio-distal diameter at } \\
\text { cervical line }=7 \mathrm{~mm}\end{array} \\
\text { Labio-lingual diameter of } \\
\text { crown }=7 \mathrm{~mm} \\
\begin{array}{l}\text { Labiolingual diameter at } \\
\text { cervical line }=6 \mathrm{~mm}\end{array}\end{array}$ & & \\
\hline Anatomical features & $\begin{array}{l}\text { Labial developmental grooves } \\
\text { Mamelons } \\
\text { Lingual fossa } \\
\text { Marginal ridges } \\
\text { Cingulum }\end{array}$ & & \\
\hline
\end{tabular}

$* 0=$ Feature is absent, $1=$ feature is present but it is incomplete or poorly defined, $2=$ Feature is clear and properly formed.

\section{STUDENT'S SATISFACTION SURVEY}

A questionnaire was modified by the authors from a study conducted by Abu Eid et al ${ }^{18}$ to gather student's feedback regarding tooth carving. The survey consisted of two parts; the first part had the questions related to demographics of the students and the second part had twelve dichotomous questions related to tooth carving.

\section{STATISTICAL ANALYSIS}

Descriptive tests were applied to the demographics of the students, such as age and gender.

Independent sample t-test was applied to compare the mean results of the scores given by the students and the examiners.

A P-value of less than 0.005 was kept as significant. The frequency of the responses to the survey was calculated by applying descriptive tests.

\section{RESULTS}

The demographics of the participants are shown in Table 02. The marks that are given by the students and the faculty are shown in Table 03 . The mean scores given by
Table 2: Demographics of the participants

\begin{tabular}{|l|l|l|l|l|}
\hline & \multicolumn{2}{|l|}{ GROUP 1 } & \multicolumn{2}{l|}{ GROUP 2 } \\
& $\begin{array}{l}\text { MALE } \\
\text { FEMALE }\end{array}$ & MALE & \multicolumn{2}{l|}{ FEMALE } \\
\hline GENDER & 10 & 11 & 9 & 12 \\
\hline AGE (MEAN \pm S.D) & $19.61(1.16)$ & $19.33(1.15)$ & \\
\hline
\end{tabular}

Table 3: Marks given by the faculty and students

\begin{tabular}{|l|l|l|l|}
\hline GROUPS & GROUP 1 & GROUP 2 & P-VALUE \\
\hline $\begin{array}{l}\text { MARKS GIVEN } \\
\text { BY FACULTY } \\
\text { (MEAN } \pm \text { S.D) }\end{array}$ & $18.7(3.11)$ & $22.9(4.38)$ & $0.001 *$ \\
\hline $\begin{array}{l}\text { MARKS GIVEN } \\
\text { BY THE } \\
\text { STUDENTS } \\
\text { (MEAN } \pm \text { S.D) }\end{array}$ & $23.6(2.59)$ & $24.8(1.79)$ & 0.092 \\
\hline
\end{tabular}

*P-value less than 0.05 is considered significant

Table 4: Student's feedback form

\begin{tabular}{|c|c|c|c|c|}
\hline \multirow[t]{2}{*}{ QUESTIONS } & \multicolumn{2}{|c|}{ GROUP 1} & \multicolumn{2}{|c|}{ GROUP 2} \\
\hline & YES & NO & YES & NO \\
\hline DO YOU LIKE CARVING? & $13(61.9)$ & $8(38.1)$ & $13(61.9)$ & $8(38.1)$ \\
\hline $\begin{array}{l}\text { DID CARVING HELPED IN } \\
\text { RECOGNIZING TOOTH LAND } \\
\text { MARKS? }\end{array}$ & $18(85.7)$ & $3(14.3)$ & $12(57.1)$ & $9(42.9)$ \\
\hline $\begin{array}{l}\text { WERE THE TOOTH PLASTER } \\
\text { MODELS HELPFUL? }\end{array}$ & $13(61.9)$ & $8(38.1)$ & $15(71.4)$ & $6(28.6)$ \\
\hline $\begin{array}{l}\text { DID THE PRACTICE OF CARVING } \\
\text { HELPED IN FAMILIARIZING TO } \\
\text { SOME LAB INSTRUMENTS? }\end{array}$ & $10(47.6)$ & $11(52.4)$ & $13(61.9)$ & $8(38.1)$ \\
\hline $\begin{array}{l}\text { WILL TOOTH CARVING HELP IN } \\
\text { IMPROVING CLINICAL SKILLS? }\end{array}$ & $9(42.9)$ & $12(57.1)$ & $13(61.9)$ & $8(38.1)$ \\
\hline $\begin{array}{l}\text { DID YOU FIND MANIPULATING } \\
\text { WAX BLOCKS EASY? }\end{array}$ & $16(76.2)$ & $5(23.8)$ & $9(42.9)$ & $12(57.1)$ \\
\hline $\begin{array}{l}\text { WAS CARVING THE CROWN THE } \\
\text { MOST DIFFICULT PART? }\end{array}$ & $11(52.4)$ & $10(47.6)$ & $9(42.9)$ & $12(57.1)$ \\
\hline $\begin{array}{l}\text { WAS CARVING THE ROOT THE } \\
\text { MOST DIFFICULT PART? }\end{array}$ & $10(47.6)$ & $11(52.4)$ & $12(57.1)$ & $9(42.9)$ \\
\hline $\begin{array}{l}\text { DO YOU THINK THAT THE } \\
\text { MARKING CRITERIA USED FOR } \\
\text { THE CARVED TOOTH WAS } \\
\text { REALISTIC? }\end{array}$ & $16(76.2)$ & $5(23.8)$ & $16(76.2)$ & $5(23.8)$ \\
\hline $\begin{array}{l}\text { DO YOU THINK CARVING } \\
\text { SHOULD BE TAUGHT IN } 1^{\text {ST }} \\
\text { YEAR? }\end{array}$ & $15(71.4)$ & $6(28.6)$ & $13(61.9)$ & $8(38.1)$ \\
\hline $\begin{array}{l}\text { DO YOU THINK THE TEACHING } \\
\text { METHODOLOGY APPLIED } \\
\text { HELPED YOU IN IMPROVING } \\
\text { YOUR SKILLS? }\end{array}$ & $15(71.4)$ & $6(28.6)$ & $18(85.7)$ & $3(14.3)$ \\
\hline $\begin{array}{l}\text { DID YOU FIND TOOTH CARVING } \\
\text { A WASTE OF TIME? }\end{array}$ & $4(19.0)$ & $17(81.0)$ & $4(19.0)$ & $17(81.0)$ \\
\hline
\end{tabular}


morphological landmarks are exaggerated and easy to locate. These models can also help in reproducing the same features on the surface of the carved tooth. The plaster models were provided to the students and in response to the question regarding its helpfulness $61.9 \%$ of students of the first group and $71.4 \%$ of students of the second group gave a positive response. This shows that enlarged tooth plaster models provide a three-dimensional teaching modality for tooth morphology that surpasses videos and other resources and can be used as a reference for tooth carving practice. When the students were enquired whether they found the crown or root part difficult in carving, they had a mixed response. In general, students found carving the root part difficult as compared to a crown. This could be attributed to the fact that root is thinner than the crown part and hence more difficult to carve and manage as it can easily be chipped off during carving. ${ }^{13}$

The majority of the students in this study agreed that tooth carving should be taught in the first undergraduate year $(71.4 \%$ and $61.9 \%$ respectively). Regarding the usefulness of the teaching methodology used, $71.4 \%$ of the students of the group I agreed that it helped improve their skills and knowledge, as it encouraged self-directed learning and experimenting. E-learning modalities like blended learning through learning management systems can provide the much-needed multi-modal approach of teaching dental anatomy(25). While $61.9 \%$ of the students of group II agreed that they preferred live demonstration of dental wax carving as it demonstrated step by step instructions.

Self-assessment of students by evaluating each other's carved teeth helped to familiarize to the marking criteria. Seventy-two per cent students of both the groups agreed that the marking criteria for dental wax carving was realistic, robust and comprehensive. Detailed analysis of all the anatomical features of a maxillary central incisor was included in the marking criteria.

A similar survey conducted by Eid et $\mathrm{al}^{18}$ on dental students reported similar results. Another survey conducted by Megahanand et $\mathrm{a}^{26}$ on dental graduates and practitioners had a similar perception of tooth carving. They also agreed that tooth carving is important for clinical skills and should be an integral component of the undergraduate dental curriculum. A strong body of evidence including a systematic review conducted on the PRISMA guidelines suggested that practical demonstration of dental wax carving along with the instructor was one of the most effective pedagogies in learning dental anatomy. ${ }^{13}$

Limitations of this study is that this study is based on a single institution. Large scale multi-centre studies are needed to generalize and validate the findings of this study.

Based on these evidence-based recommendations, dental wax carving should be an integral component of the dental curriculum in Pakistan as it promotes early pre-clinical skills development commensurate with longitudinal integration and is an effective pedagogy for learning practical dental anatomy.

\section{CONCLUSION}

Based on results of this study, dental wax carving was found to be an effective pedagogical strategy to develop preclinical psychomotor skills of dental students by recreating tooth morphological characteristics in wax. The progress of students will be followed through their clinical skills and subsequently into their clinical work. It is therefore imperative that tooth carving be included in the national dental curriculum so that longitudinal or spiral integration can take place.

\section{CONFLICT OF INTEREST}

None declared

\section{REFERENCES}

1. Nance ET, Lanning SK, Gunsolley JC. Dental anatomy carving computer-assisted instruction program: an assessment of student performance and perceptions. J Dent Educ. 2009;73:972-79. https://doi.org/10.1002/j.0022-0337.2009.73.8.tb04786.x

2. Obrez A, Briggs C, Buckman J, Goldstein L, Lamb C, Knight WG. Teaching clinically relevant dental anatomy in the dental curriculum: description and assessment of an innovative module. J Dent Educ. 2011;75:797-804.

https://doi.org/10.1002/j.0022-0337.2011.75.6.tb05108.x

3. Rubinstein S, Nidetz A. The art and science of the direct posterior restoration: recreating form, color, and translucency. The Alpha omegan. 2007;100:30-5.

https://doi.org/10.1016/j.aodf.2006.07.001

4. Capote T, Barroso R, Pinto S, Conte M, Campos J, Bolini P, et al. A Contribution to the Anatomical Study of the Mandibular Premolars. J Morphological Sci. 2018;35:58-63.

https://doi.org/10.1055/s-0038-1660493

5. Gansky SA, Pritchard H, Kahl E, Mendoza D, Bird W, Miller AJ, et al. Reliability and validity of a manual dexterity test to predict preclinical grades. J Dent Educ. 2004;68:985-94.

https://doi.org/10.1002/j.0022-0337.2004.68.9.tb03848.x

6. Giuliani M, Lajolo C, Clemente L, Querqui A, Viotti R, Boari A, et al. Is manual dexterity essential in the selection of dental students? British Dent J. 2007;203:149.

https://doi.org/10.1038/bdj.2007.688

7. Schroeter C. Practical application of tooth morphology. J Prosthetic 
Dentistry. 1959;9:867-73.

https://doi.org/10.1016/0022-3913(59)90053-8

8. Kilistoff A. A systematic technique for carving amalgam and composite restorations. Opera Dentis. 2011;36:335-39.

https://doi.org/10.2341/10-311-T

9. Lone M, McKenna J, Cryan J, Downer E, Toulouse A. A Survey of tooth morphology teaching methods employed in the United Kingdom and Ireland. Eur J Dent Educ. 2018.

https://doi.org/10.1111/eje.12322

10. Permar D. Tooth form drawing and carving. A manual: By Russell C. Wheeler. 106 pages with 124 illustrations. Philadelphia and London, WB Saunders Co., 1954. J Prosthet Dentis. 1954;4:855. https://doi.org/10.1016/0022-3913(54)90051-7

11. Siéssere S, Vitti M, Sousa LGd, Semprini M, Regalo SCH. Educational material of dental anatomy applied to study the morphology of permanent teeth. Brazilian Dent J. 2004;15:238-47. https://doi.org/10.1590/S0103-64402004000300014

12. Patil S, Sowmya S, Rao RS, Raj T. Knowledge, attitude and practice of tooth morphology among dental students. J Adv Clin Res Insights. 2015;2:124-30.

https://doi.org/10.15713/ins.jcri.60

13. de Azevedo RA, Correa MB, Torriani MA, Lund RG. Optimizing quality of dental carving by preclinical dental students through anatomy theory reinforcement. Anat Sci Educ. 2018;11:377-84.

https://doi.org/10.1002/ase.1752

14. Ennes JP, Souza AS, Cunha IPd, Nacasato RP, Gardim DCM. Teaching tools in dental carving: models, virtual resources, and interactivity. Rev ABENO. 2018;18:45-55.

https://doi.org/10.30979/rev.abeno.v18i1.478

15. Zhang M, Zhou J, Cheng F, Shi Z. Comparison of two carving methods applied for triple-sized plaster tooth in dental anatomy teaching. Shanghai kou qiang yi xue $=$ Shanghai J Stomatol. 2006;15:551-4.

16. Campbell AJ, Diep C, Reinken J, McCosh L. Factors predicting mortality in a total population sample of the elderly. J Epidemiol Community Health. 1985;39:337-42.

https://doi.org/10.1136/jech.39.4.337

17. Kilistoff AJ, Mackenzie L, D'Eon M, Trinder K. Efficacy of a step-by-step carving technique for dental students. J Dent Educ. 2013;77:63-7.

https://doi.org/10.1002/j.0022-0337.2013.77.1.tb05444.x

18. Eid RA, Ewan K, Foley J, Oweis Y, Jayasinghe J. Self-directed study and carving tooth models for learning tooth morphology: Perceptions of students at the University of Aberdeen, Scotland. J Dent Educ. 2013;77:1147-53.

https://doi.org/10.1002/j.0022-0337.2013.77.9.tb05586.x

19. Curricular guidelines for oral biology. J Dent Educ. 1984;48:26973.

https://doi.org/10.1002/j.0022-0337.1984.48.5.tb01789.x

20. Wright EF, Hendricson WD. Evaluation of a 3-D interactive tooth atlas by dental students in dental anatomy and endodontics courses. J Dent Educ. 2010;74:110-22.

https://doi.org/10.1002/j.0022-0337.2010.74.2.tb04860.x

21. Nagasawa S, Yoshida T, Tamura K, Yamazoe M, Hayano K, Arai $\mathrm{Y}$, et al. Construction of database for three-dimensional human tooth models and its ability for education and research-Carious tooth models. Dent Mater J. 2010;29:132-37.

https://doi.org/10.4012/dmj.2009-013

22. Mitov G, Dillschneider T, Abed MR, Hohenberg G, Pospiech P. Introducing and evaluating MorphoDent, a Web-based learning program in dental morphology. J Dent Educ. 2010;74:1133-9.

https://doi.org/10.1002/j.0022-0337.2010.74.10.tb04968.x

23. Sivapathasundharam B. Tooth carving. Indian J Dent Res. 2008;19:181.

https://doi.org/10.4103/0970-9290.42946

24. Moretto SG, de Almeida Anfe TE, Nagase DY, Kuguimiya RN, Lago ADN, Freitas PM, et al. Theoretical knowledge versus practical performance in dental sculpting-preliminary study. Clin Lab Res Dentis. 2014;20:82-7.

https://doi.org/10.11606/issn.2357-8041.v20i2p82-87

25. Baig QA, Zaidi SJA, Alam BF. Perceptions of dental faculty and students of E-learning and its application in a public sector Dental College in Karachi, Pakistan. J Pak Med Assoc. 2019.

26. Nayak MT, Sahni P, Singhvi A, Singh A. The perceived relevance of tooth carving in dental education: Views of practicing dentists and faculty in West India. Educ for Health. 2014;27:238.

https://doi.org/10.4103/1357-6283.152177 